(2) OPEN ACCESS

Radiology, University Hospitals Plymouth NHS Trust, Plymouth, UK

\section{Correspondence to Dr Vilim Kalamar: vilim.kalamar@nhs.net}

Accepted 15 September 2021

\title{
MRI findings seen in serous atrophy of bone marrow
}

\author{
Vilim Kalamar ำ , Alun Davies, Peter Wright, Priya Suresh
}

\section{SUMMARY}

An 85-year-old man was referred for an MRI scan of the pelvis for further evaluation of a suspected left neck of femur fracture, which was regarded as equivocal on plain radiograph and $\mathrm{CT}$. The initial MRI demonstrated unusual appearances of the visualised bone marrow and subcutaneous adipose tissue and was initially misinterpreted as a technical malfunction of the scanner. However, a repeat study on a different scanner the following day once again demonstrated the same appearances. The appearances were consistent with serous atrophy of bone marrow, a non-neoplastic disorder of the bone marrow, which is most commonly seen in severe anorexia nervosa or cachexia. These unusual, but distinct, bone marrow and subcutaneous adipose tissue appearances, which are specific to MRI, have been colloquially termed as the 'flip-flop' effect.

\section{BACKGROUND}

The appearance of diffuse bone marrow abnormalities on MRI in regular clinical practice is not uncommon-nor are technical errors in the current age of computers and information technology. This case report highlights an unexpected occurrence of the so-called 'flip-flop' effect-a significant, but under recognised, MRI entity seen in the condition of serous atrophy of bone marrow (SABM). SABM is an uncommon, and potentially reversible, cause of diffuse changes in the bone marrow and subcutaneous adipose tissue. We share with you what transpired at our institution and we will describe some differential diagnoses and learning points regarding how to problem solve if faced with these unusual, but distinct, MRI appearances.

\section{CASE PRESENTATION}

An 85-year-old man, with a medical history of inflammatory bowel disease which required treatment with corticosteroids and bowel resection, was referred to orthopaedics with left hip pain following a fall. More recently, the patient developed irondeficiency anaemia, mild heart failure, malnutrition, frailty and weight loss. Three months prior to their fall, due to their iron-deficiency anaemia and weight loss, the patient had a CT scan of the thorax abdomen and pelvis with intravenous contrast to investigate for disseminated malignancy, however, no malignancy was found.

\section{INVESTIGATION}

On the day of the patient's fall and admission, a plain radiograph of the hip was performed to investigate for a left neck of femur fracture. Acute fractures of the left superior and inferior pubic rami and left S2 sacral arcade were demonstrated, however, appearances of the left femoral neck were equivocal (figure 1). Since the plain radiograph was indeterminate for a neck of femur fracture, a CT scan of the pelvis was performed for further evaluation. The CT confirmed the three fracture sites listed above, however, the appearances of the left femoral neck remained equivocal. Blood tests demonstrated that the patient had a low haemoglobin of $84 \mathrm{~g} / \mathrm{L}$ (reference: $130-180 \mathrm{~g} / \mathrm{L}$ for an adult male) and a profound hypoalbuminaemia of $22 \mathrm{~g} / \mathrm{L}$ (reference: 34-54 g/L). Kidney function tests, lactate level and COVID-19 swab were all normal. The patient also demonstrated normal clinical observations.

Two days later, due to ongoing clinical concerns regarding the left neck of femur, an MRI scan of the pelvis was requested and performed to specifically interrogate for an occult fracture. The initial report described the bone marrow and subcutaneous adipose tissue appearances as unusual and suspected a technical malfunction by stating that the T1-weighted sequence looked like there was fat suppression applied when there was not (figure $2 \mathrm{~A}$ ) and that the short tau inversion recovery (STIR) sequence (figure 2B) was unexpectedly not suppressing fat. The radiographers performing the scan also suspected a technical malfunction. Therefore, another MRI scan was arranged the following day, specifically on a different scanner, to evaluate these findings further. The repeat scan demonstrated the same appearances. It was then recognised that the appearances represented SABM which can be seen in severe anorexia or cachexia and many other conditions. ${ }^{1-8}$ Unfortunately, it was once again very challenging to interpret whether an occult femoral neck fracture was present because identifying focal bone marrow oedema on a fluid-sensitive MRI sequence, indicative of an acute fracture, could not be confidently done in the presence of such extensive background bone marrow abnormality.

\section{DIFFERENTIAL DIAGNOSIS}

In addition to the aforementioned misinterpretation of these appearances as a result of a perceived technical error with the MR system, other important differentials should be considered and distinguished from one another. These include: malignant marrow infiltration, infection and radiation-induced changes in the bone marrow. ${ }^{14}$

SABM and malignant marrow infiltration are distinguished from each other primarily by their locations. Malignant marrow infiltration has an affinity for red marrow residing in the axial 


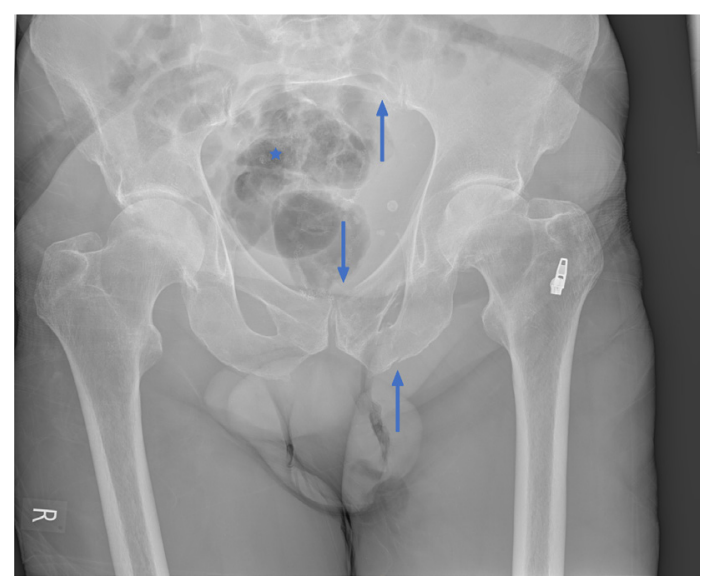

Figure 1 Plain radiograph of the pelvis demonstrating acute fractures of the left superior and inferior pubic rami and left S2 sacral arcade (blue arrows), but is equivocal for an acute left neck of femur fracture. Anastomotic staples from previous bowel resection are also demonstrated (blue star).

skeleton and SABM changes are specifically and predominantly seen in the appendicular skeleton with additional subcutaneous adipose tissue involvement. ${ }^{14}$ Additionally, serous marrow does not enhance after administration of intravenous contrast, differentiating it from diffuse infiltrating malignancy. ${ }^{8}$

Infection, specifically osteomyelitis, also causes replacement of normal fatty marrow on MRI. Normal cortical bone is low signal on all conventional clinical MRI sequences, so infection could be suspected if involved bone marrow and cortices demonstrated interval focal high signal on fluid-sensitive sequences due to reactive inflammatory oedema. Additionally, the administration of intravenous gadolinium contrast helps to delineate fluid collections and evaluate for presence of sequestrum, which is non-enhancing necrotic bone. Infection was not clinically suspected in this case because the patient had normal clinical observations and normal inflammatory markers throughout their hospital admission.

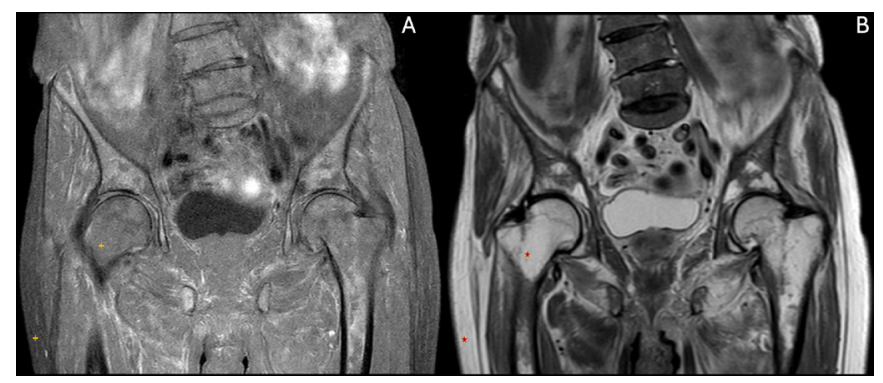

Figure 2 (A) Coronal T1-weighted MRI sequence demonstrating lack of normal fat signal within the trabecular bone and subcutaneous adipose tissue (yellow crosses). The subcutaneous adipose tissue appears uniformly grey here-falsely mimicking the application of fatsuppression when it has not been applied. Note the low signal intensity of the urine in the bladder, consistent with a T1-weighted sequence. (B) Coronal STIR MRI sequence demonstrating high signal intensity within the trabecular bone and subcutaneous adipose tissue (red stars) indicating the presence of fluid-density substance rather than fat. Note the high signal intensity of the urine in the bladder, consistent with an STIR sequence. STIR, short tau inversion recovery.
Radiation-induced changes in the bone marrow on MRI are time and dose dependent. ${ }^{9}$ Acutely, 1-3 days post-irradiation, the affected bone marrow develops oedema, which appears hypointense on T1-weighted sequences and hyperintense on fatsaturated T2-weighted and STIR sequences, similar to SABM. However, as early as 10-14 days, but up to months later, bone marrow within the irradiated field undergoes expedited conversion to fatty marrow, which would distinguish it from SABM. ${ }^{9}$ We ruled this out by confirming that our patient had no history of radiotherapy.

Despite these differential diagnoses being considered, the experienced reporting musculoskeletal radiologist had the advantage of a repeat scan from the previous day showing the same imaging appearances so they were able to more confidently diagnose SABM. However, since it is rarely seen, especially in the age group of our patient, a haematological review was still sensibly advised. The review confirmed the patient's known iron-deficiency anaemia, hypoalbuminaemia and absence of diffuse, marrow-infiltrating malignancy.

\section{TREATMENT}

During their admission, the patient improved with physiotherapy and simple analgesia. As a result, they were managed conservatively and discharged, without orthopaedic surgical intervention, to a local community hospital for further physiotherapy. They also received an injection of intravenous ferric carboxymaltose and one unit of packed red blood cells which improved their anaemia biochemically and clinically.

\section{OUTCOME AND FOLLOW-UP}

Since the initial hospitalisation, the patient had another two admissions related to falls. On the second admission, three months later, the patient unequivocally fractured their right neck of femur and had a hemiarthroplasty inserted. They were discharged to a community hospital for physiotherapy and then into a residential care home. The patient was soon after rehospitalised once again and sadly passed away due to frailty.

\section{DISCUSSION}

SABM is a rare, and potentially reversible, cause of diffuse, irregular bone marrow and subcutaneous adipose tissue appearances on MRI. ${ }^{2}$ It is largely an incidental imaging entity which would likely never be specifically raised as a specific clinical question necessitating a MRI scan. SABM has also been termed gelatinous bone marrow transformation or 'starvation marrow'. The underlying pathogenesis is not completely understood and it may be a non-specific indicator of severe illness. ${ }^{127}$ Although there are many cited causes, the vast majority of literature is centred around anorexia nervosa and malnutrition, and states that most cases occur under the age of 30 with male predominance. ${ }^{1-7}$ Only a handful of cases within the literature have been reported in patients over the age of 80 , which makes this case very rare. ${ }^{2}$ SABM is often clinically associated with weight loss and anaemia and carries a higher risk for lower limb fractures; all of which were either present in this case at the time of initial imaging, or subsequently occurred shortly after. ${ }^{12}$

Although strict imaging diagnostic criteria have never been established for SABM, expected appearances on MRI are characteristic. As seen in this case, these include mildly hypointense signal intensity in the bone marrow and subcutaneous adipose tissue on T1-weighted sequences (figure 2A) with hyperintense signal intensity in the bone marrow and subcutaneous 
adipose tissue on fluid-sensitive T2-weighted or STIR sequences (figure 2B). ${ }^{13710}$ The MRI appearances of the bone marrow are secondary to aggregation of extracellular gelatinous and watery substance, confirmed to be predominantly hyaluronic acid mucopolysaccharides. There is also focal loss of marrow fat and haematopoietic cells. ${ }^{2}{ }^{4}$ These histochemical changes result in increased fluid and reduced fat signal contribution, leading to increased T1 and T2 relaxation times. ${ }^{4}$ The subcutaneous adipose tissue can appear uniformly grey on T1-weighted sequences-falsely mimicking the application of a fat-suppression sequence, when there is not one actually applied, and the genuinely fat-suppressed STIR sequence can appear to have failed at suppressing fat signal. In reality, the patient has clinically severe fat depletion. Additional suggested explanations for the appearances of the subcutaneous adipose tissue include: replacement of adipose tissue with loose vascular tissue, increased vascular permeability, heart failure and volume shifts secondary to electrolyte derangements and hypoalbuminaemia. ${ }^{13}$ Due to these unusual appearances, the term 'flip-flop' effect has been utilised within the literature. ${ }^{3} 10$

It is our main practical aim to decrease incidence of misinterpreting these MRI appearances as a technical malfunction and thus potentially prevent subjecting a patient to unnecessary additional or repeated imaging, such as what occurred at our institution on this occasion. Misinterpretation and recall rates have been shown to be as high as $23 \%{ }^{1}$

MRI is currently the gold standard for detecting radiographically occult fractures. ${ }^{11}$ However, we would like to highlight once again that assessing for complications such as fractures can be incredibly challenging on the background of such diffusely abnormal bone marrow signal changes seen in SABM. Potential occult fractures are essentially camouflaged.

Learning points

- The 'flip-flop' effect describes unusual MRI appearances seen in serous atrophy of bone marrow (SABM) which can initially be misinterpreted as a technical malfunction within the MR system or for a diffuse infiltrating malignancy.

- The main practical aim is to decrease incidence of misinterpreting these MRI appearances as a technical malfunction and thus potentially prevent unnecessary additional or repeated imaging. If in doubt, seek another experienced colleague's opinion.

- It is very challenging to diagnose acute occult trabecular fractures on fluid-sensitive MRI sequences in the presence of such diffusely abnormal appearing bone marrow seen in SABM since the expected focal bone marrow oedema associated with these fractures is essentially camouflaged.

- Fluid-filled structures such as the bladder or the spinal canal can be used as a reference to assist determining the weighting of an MRI sequence.

- Spectroscopic analysis or Dixon technique are additional problem-solving techniques to confirm presence of high intramedullary fluid content and subcutaneous fat depletion seen in SABM.
Finally, additional problem-solving techniques such as MR spectroscopy and Dixon technique can also be used. In spectroscopy, rather than both profound lipid and water peaks, a small lipid peak and a profound water peak would be expected in SABM. For the Dixon technique, which exploits the chemical shift of water and lipid molecules, the lipid-poor and fluid-rich tissues seen in SABM can be confirmed. ${ }^{4}{ }^{12}$ However, it should be noted that the two point Dixon technique can suffer from fat-water swapping artefact in areas of main magnetic field inhomogeneity, so it is recommended to use a three-point Dixon technique to avoid any further confusion. ${ }^{12} 13$

Acknowledgements Thank you Dr Suresh, Dr Davies and Dr Wright for your incredible support in writing this case report. It was a great pleasure to work with all of you. Thank you Dr Sarath Vennam and Dr Andrew MacCormick for providing technical support and advice. Thank you to the patient and their son for their incredibly kind interactions with us. I'd like to extend a final thank you to the Peninsula Radiology Academy as a teaching institution.

Contributors PS: case identification. VK (corresponding author): initial draft and implementing all changes to the manuscipt following consistent input and revision from all other listed authors (AD/PW/PS).

Funding The authors have not declared a specific grant for this research from any funding agency in the public, commercial or not-for-profit sectors.

Competing interests None declared.

Patient consent for publication Consent obtained from next of kin.

Provenance and peer review Not commissioned; externally peer reviewed.

Open access This is an open access article distributed in accordance with the Creative Commons Attribution Non Commercial (CC BY-NC 4.0) license, which permits others to distribute, remix, adapt, build upon this work non-commercially, and license their derivative works on different terms, provided the original work is properly cited and the use is non-commercial. See: http://creativecommons.org/ licenses/by-nc/4.0/.

\section{ORCID iD}

Vilim Kalamar http://orcid.org/0000-0002-1432-9275

\section{REFERENCES}

1 Boutin RD, White LM, Laor T, et al. MRI findings of serous atrophy of bone marrow and associated complications. Eur Radiol 2015;25:2771-8.

2 Böhm J. Gelatinous transformation of the bone marrow: the spectrum of underlying diseases. Am J Surg Pathol 2000;24:56.

3 DiVasta AD, Mulkern RV, Gordon CM, et al. MR Imaging in a case of severe anorexia nervosa: the 'flip-flop' effect. Pediatr Radiol 2015;45:617-20.

4 Vande Berg BC, Malghem J, Devuyst 0, et al. Anorexia nervosa: correlation between $\mathrm{Mr}$ appearance of bone marrow and severity of disease. Radiology 1994;193:859-64.

5 Ecklund K, Vajapeyam S, Mulkern RV, et al. Bone marrow fat content in 70 adolescent girls with anorexia nervosa: magnetic resonance imaging and magnetic resonance spectroscopy assessment. Pediatr Radiol 2017;47:952-62.

6 Munfus DL, Menke DM. Case of severe serous fat atrophy. In: Mayo clinic proceedings. Elsevier, 2009: 570.

7 CY N, Kuek DKC, Suresh P. Mr findings in the bone marrow of a patient with anorexia nervosa. Indian J Musculoskelet Radiol;2.

8 Palmer W, Bancroft L, Bonar F, et al. Glossary of terms for musculoskeletal radiology. Skeletal Radiol 2020;49:1-33.

9 Daldrup-Link HE, Henning T, Link TM. MR imaging of therapy-induced changes of bone marrow. Eur Radiol 2007;17:743-61.

10 Varotto A, Vitale V, Mansour M, et al. Spinal 'flip-flop' effect in anorexia nervosa: A case report. J Med Imaging Radiat Oncol 2020;64:534-6.

11 Jarraya M, Hayashi D, Roemer FW, et al. Radiographically occult and subtle fractures: a pictorial review. Radiol Res Pract 2013;2013:1-10.

12 Ma J. Dixon techniques for water and fat imaging. J Magn Reson Imaging 2008;28:543-58

13 Kirchgesner T, Acid S, Perlepe V, et al. Two-Point Dixon fat-water swapping artifact: lesion mimicker at musculoskeletal T2-weighted MRI. Skeletal Radiol 2020;49:2081-6. 
Copyright 2021 BMJ Publishing Group. All rights reserved. For permission to reuse any of this content visit https://www.bmj.com/company/products-services/rights-and-licensing/permissions/

BMJ Case Report Fellows may re-use this article for personal use and teaching without any further permission.

Become a Fellow of BMJ Case Reports today and you can:

- Submit as many cases as you like

- Enjoy fast sympathetic peer review and rapid publication of accepted articles

Access all the published articles

- Re-use any of the published material for personal use and teaching without further permission

Customer Service

If you have any further queries about your subscription, please contact our customer services team on +44 (0) 2071111105 or via email at support@bmj.com.

Visit casereports.bmj.com for more articles like this and to become a Fellow 